\title{
An evaluation of the reporting on ethics and integrity of selected listed motor vehicle companies
}

Author:

Prof. Anet Magdalena Smit ${ }^{1}$ Ms Elizabeth J. Bierman ${ }^{1}$

\section{Affiliation:}

${ }^{1}$ North-West University, South Africa

\section{Correspondence to:}

Prof. Anet Magdalena Smit, School of Business and Governance,

North-West University, Potchefstroom Campus, Private Bag X6001, Potchefstroom 2520, South Africa

\section{E-mail:}

anet.smit@nwu.ac.za

ORCID iD:

http://orcid.org/0000-00024358-8583

DOI:

$10.15249 / 11-1-152$

\section{Keywords:}

sustainability; Global Reporting Initiative (GRI); ethics; integrity; anti-corruption; triple bottom line (TBL) reporting; Corporate Social Responsibility (CSR); integrated reporting

\section{Abstract}

Transparency in reporting has become very important and various stakeholders expect companies to disclose sensitive information, such as ethical aspects, integrity and anticorruption information. Any indication of corruption can be detrimental when trying to attract foreign investors to invest in a country. These disclosure practices could place remarkable pressure on a company that needs to portray a positive image to their stakeholders. The main objective of this research was to evaluate the reporting on ethics, integrity and anticorruption of companies in the motor vehicle manufacturing sector. Content analysis was used as the research method. A checklist was compiled based on the different frameworks and country requirements. The results of the evaluation indicate that companies understand the importance of the governance aspects such as ethics and integrity, and some also provide training on the relevant codes and policies. However, disclosure on corruption-related incidents within the companies is substandard and insufficient information is provided in the reports.

\section{Introduction}

Several factors have served as motivation for companies to change their reporting format, such as new guidelines and regulations, investor or customer expectations, internal commitment to sustainability, better risk management and the desire to increase consumer and employee loyalty. Goodwill received from being transparent and the desire to remain competitive are also factors that drive changes in reporting behaviour (Lynch, Lynch \& Casten, 2014). Companies are 
now expected to increase their reporting on sustainability issues and are experiencing pressure through regulations enforced by institutions or government, as well as pressure from shareholders (English \& Schooley, 2014). One aspect that is crucial to the long-term sustainability of a business is to operate with integrity and without corruption.

The concept of accounting for sustainability (A4S) was introduced by his Royal Highness, the Prince of Wales, in 2004 (Hughen, Lulseged \& Upton, 2014). One of the problems preceding the $\mathrm{A} 4 \mathrm{~S}$ project was that financial systems focused on short-term financial performance rather than on the long-term health of communities and the environment. Consequently, some companies and stakeholders have started to move towards an improved understanding that the goal should be to work towards long-term sustainability of economic, social and environmental factors (His Royal Highness the Prince of Wales, 2015; Hughen, Lulseged \& Upton, 2014). Subsequently, triple bottom line (TBL) or sustainability reporting emerged and has since become a growing trend (Mintz, 2011).

Stakeholders and investors were shocked by financial scandals such as the Enron scandal, as well as the Volkswagen (VW) scandal, which urged stakeholders to demand more detail on financial as well as non-financial information (Hughen et al., 2014). In the context of this study the focus will be on information that should be reported on in terms of integrity and corruption. Although sustainability reporting is still in its early stages, it is not likely to disappear soon (Tschopp \& Huefner, 2015). Given its importance, and the increasing needs and demands of stakeholders, organisations should address matters of sustainability in a proper manner, and attend to the reporting criteria that include transparency, completeness, truth and clarity, substance, continuity and comparability. Quality reporting should reflect relevant information, corporate governance, honesty, risk management and reputation issues (Sukitsch, Engert \& Baumgartner, 2015). Previous studies by Junior, Best and Cotter (2014) indicated that an independent validation of the sustainability report increases credibility. The credibility could even be further improved if validation is done externally by a well-known accounting firm. Validation of sustainability reports is a fairly new concept and is not regulated in most countries (Junior et al., 2014). There is a lack of criteria for auditing firms to perform this kind of validation (Romero, Jeffers \& DeGaetano, 2014).

\section{Background}

Considering financial scandals such as Cendent (1998), Xerox (2000), Enron (2001), AIG (2004), Lehman Brothers (2010) and, more recently, the Volkswagen (VW) scandal in 2015 , it is evident that an era of fraud has begun and has become a matter of concern in modern-day society (Mironiuc, Chersan \& Robu, 2013). This has created a greater need for transparency in reporting on financial as well as non-financial information (Mironiuc et al., 2013).

Also in the motor vehicle manufacturing sector, there are growing concerns regarding noise pollution, waste disposal problems, impact on air quality and other environmental 
impacts (Kehbila, Ertel \& Brent, 2010). These problem areas focus on sustainability, and in this sense also on the quality of disclosure in sustainability reporting (Kehbila et al., 2010). Ethics and integrity is an integral part of business today and adds value to the transparency of reporting on Corporate Social Responsibility (CSR) issues. The connection between CSR activities, ethics and integrity is that both are issues of moral responsibility and should be reported on. The study of Mpinganjira, Roberts-Lombard, Wood \& Svensson (2015) highlighted the importance of a unified approach to business ethics across all sectors of society.

\section{Reporting on ethics, integrity and anti-corruption}

\subsection{Ethics and integrity}

Business ethics is an issue that concerns all entities. When companies behave ethically, it is regarded as good business practice. Companies, in their movement towards more than just compliance, introduced different actions such as codes of conduct, codes of ethics, ethics committees and even providing training to employees with regard to ethics and integrity (Tinjala, Pantea \& Alexandru, 2015). Integrity is more of a personal trait and is closely linked to a personal code of conduct. It is an internal system of principles, with the reward mostly being intrinsic to the employee. Integrity is founded on a set of core principles, ensuring behaviour of a consistently high standard. These principles include qualities such as compassion, dependability, honesty, loyalty, respect, trust and wisdom (Czimbal \& Brooks, 2006). In this study, the GRI guidelines on ethics and integrity as required qualities in an organisation, and not on a personal level, are reviewed.

Ethics is often referred to when there is an array of people representing the company and it is the appropriate tool to manage their behaviour (Navratil, 2007). The expectation from the greater society is that companies should not just respect laws, but also share the ethical standards of the community. The reward is often not just a good reputation, but also adds to the competitive advantage and the bottom line of a company (Tinjala et al., 2015). When ethics and integrity are combined in an organisation, a positive orientation is normally the result whereas, without ethics and integrity, corruption is often the result (Czimbal \& Brooks, 2006).

The governance code or code of conduct of a company should also include mechanisms whereby employees can expose any unethical behaviour or business practices (Tinjala et al., 2015). The most common form of these mechanisms is a whistle-blowing programme. Any person, be it an employee, a manager, supplier or customer, who becomes aware of illegal activities taking place within a company can report this to the ethics committee or to the governing body.

Numerous studies have indicated that leaders in an organisation play a pivotal role in shaping sustainable ethical behaviour. These leaders introduce the ethical standards and show ethical values in all their decision-making. Ethical leaders' lead ethical organisations and an effective ethical organisation has effective leaders that "walk the talk". An ethical 
culture is characterised by ethical leaders that are non-retaliatory, but expect mutuality of ethical behaviour from all stakeholders (Jondle, Ardichvili \& Mitchell, 2014). An ethical culture includes components such as rules, codes of ethics, policies and disciplinary procedures, and is based on shared accountability and a clear code of conduct that is well communicated and understood (Appel \& Plant, 2015). Information with regard to ethical behaviour is provided to the investors or stakeholders through media or corporate reports such as CSR reports, where companies can decide on how transparently they disclose information (Tinjala et al., 2015). The importance of ethics and integrity have been emphasised in the latest King IV Report. In Part 5, that deals specifically with the Code on Corporate Governance, the first principle is that the governing body should lead ethically and effectively (IOD, 2016). The second principle also deals with ethics and states that the governing body should govern the ethics in an organisation and that it should establish an ethical culture in the organisation (IOD, 2016).

\subsection{Corruption}

Corruption starts with non-ethical actions being ignored by the company. Some even go so far as to discover the corruption and then conceal the non-ethical actions (Walcher, Stempkowski \& Apflater, 2013). In the case of Volkswagen's emission scandal, the company even went to the extent of deceiving external monitoring bodies to conceal fraudulent and corrupt activities. Corruption can be viewed as a result of an ineffective governance framework. The framework should promote transparency, integrity and accountability. For instance, whistle-blowing systems should be implemented at all levels of the organisation and should include means for reporting suspicious activity (Walcher et al., 2013).

The effects of corruption are evident in reputational, social, financial and economic results. Reputational damage is difficult to measure but when information becomes publicly available, it often results in substantial, lasting damage to the company. In the case of Volkswagen, other countries were annoyed and wanted to prosecute the company for violating the sustainability concept. There were also concerns that the scandal could negatively affect the economic growth of Germany. The worst consequence resided in the financial implications the company had to bear. Although the Economy Minister, Sigmar Gabriel, was of the opinion that it would not cause permanent damage, Germany has experienced the negative consequences (Eyewitness News, 2016).

There are various frameworks of reporting, such as the Global Reporting Initiative (GRI), Carbon Disclosure Project (CDP) and the Sustainability Accounting Standards Board (SASB). Although none of these is mandatory, there seems to be a large movement towards companies adopting these reporting initiatives and producing sustainability reports according to these guidelines in order to avoid fraudulent acts and reputational damage (Pandit \& Rubenfield, 2016). The GRI states that the assurance of a report can provide greater confidence in the disclosed information, although having a report validated is also not mandatory. In a study done by Pandit and Rubenfield (2016) on a hundred smaller S\&P 500 companies, they point out that only $35 \%$ of companies disclosed information 
on ethical practices, compliance and governance. Volkswagen provided information in its sustainability report during 2014 and had it validated by PricewaterhouseCoopers and was still caught on 18 September 2015 when they admitted introducing software aimed at fraudulent tests on gas emissions by their diesel vehicles.

If all companies ensure transparency of their business practices and communicate ethics, integrity and anti-corruption, areas of irregularities could become more transparent. Some misconduct could be eliminated, depending on the validity and integrity of the data supplied by an organisation. According to Russo-Spena, Tregua and De Chiara (2016) Corporate Social Responsibility (CSR) reporting remains a dynamic and controversial domain, where authors focus on different aspects. They also urge caution towards companies who manipulate their disclosure and only report positive actions or provide a so-called "greenwashed" report.

\section{Sustainability frameworks}

Various frameworks have been developed to enhance reporting as variability of reports made it difficult to compare information from different companies (Mintz, 2011). Global standards tend to ensure that investors can perform more comprehensive comparisons between companies. But despite the various organisations involved, frameworks and guidelines that have been developed for companies to report and disclose information, comparability remains an issue.

The GRI's main objective was to create a global sustainability reporting framework that could be applied to all companies worldwide (Godha \& Jain, 2015). According to Godha and Jain, the GRI can be viewed as the most widely used standard for sustainability reporting and this is confirmed by Junior et al. (2014), who view it as the most commonly utilised guideline on sustainable reporting. The GRI guidelines can be used by all types of companies, across various sectors, independent of size or nature and can be applied at different application levels (Tschopp \& Huefner, 2015; Junior et al., 2014). The most recently released guidelines are the G4 guidelines, which include aspects on anti-corruption. The G4 guidelines also place an emphasis on materiality, stating the necessity to report on areas material to the organisation, instead of reporting on everything (English \& Schooley, 2014).

One of the frameworks that is used in the United States of America (USA), is the Sustainability Accounting Standards Board (SASB). Publicly listed companies use the SASB accounting standards to disclose sustainability information that is already highly in demand (Schooley \& English, 2015). Another framework is the Carbon Disclosure Project (CDP) which is also a non-profit organisation. The CDP utilises information that is disclosed by companies and tries to make the information more measurable and to manage future risks (Bartels, Fogelberg \& Hoballah, 2016; Van der Lugt, 2016). The CDP's scores assess a company's reports based on the quality and completeness of all the disclosures made in the report (Siew, 2015). The influence from the CDP has 
led to a global movement for companies to measure and disclose their greenhouse gas emissions, climate-change risk and water strategies (Bartels et al., 2016). The Greenhouse Gas Protocol (GHG) is another accounting tool that enables governments and companies to understand, measure and manage their greenhouse gas emissions. (Greenhouse Gas Protocol, 2016). ISO 26000 is an additional standard that provides voluntary guidelines with regard to social responsibility. The content of the ISO 26000 guidelines is very similar to the aspects included in the GRI reporting guidelines. The ISO 26000 can be used as a structure to align activities, which will then be reported at a later stage (GRI and ISO 26000, 2010).

Steering away from individual reports has created the trend for combining financial and non-financial information in one report, referred to as an integrated report (Anderson $\&$ Varney, 2015). The rationale behind integrated reporting is to enable stakeholders to view and assess the organisation's capability to create and sustain value over the short, medium, and long term, without depleting the resources of the business (Owen, 2013; Bouten \& Hoozée, 2015; Hughen et al., 2014).

\section{Reporting requirements in different countries}

The twenty motor vehicle manufacturing companies that were identified for the purpose of this study are based in different countries, which include Germany, France, Italy, UK, USA, India, Japan, South Korea and Sweden. France and Denmark were some of the countries that had already adopted national laws on CSR reporting. Previously, research was done by a group of partners, including UNEP, GRI, KPMG, and the Centre of Corporate Governance in Africa, on sustainability reporting policies worldwide. (Fogelberg, Bartels, Lemmet, Malan \& Van der Lugt, 2013). The research revealed the following mandatory and voluntary guidelines per country, from their study:

\subsection{Germany}

Germany has still not instructed CSR reporting as mandatory, although many of the larger companies in Germany are well-known for their CSR efforts. In 2012, the German motor vehicle manufacturer BMW was identified as the "greenest" vehicle manufacturer in seven years (Beier, 2012). Germany introduced the German Sustainability Code (GSC) as voluntary guidelines, encouraging companies to report sustainability under 20 principles, which is in line with GRI, UN Global Compact, OECD guidelines for Multinational Companies, as well as the ISO 26000 guidelines (Fogelberg et al., 2013). Other mandatory frameworks include the Bilanzrechtsreformgesetz (BilReG), the German Accounting Standard No. 20 (GAS 20).

\subsection{France}

Large companies in France are mandated to produce annual CSR reports. Main international guidelines accepted include ISO 26000, Global Compact principles, the 
guiding principles of human rights and business, OECD Guidelines for Multinational Enterprises, and GRI (Fogelberg et al., 2013). Other mandatory guidelines include mandatory CSR reports for all listed companies, the New Economic Regulations Act (NRE), with 40 indicators inspired by the GRI and the General Law Article 18 for listed companies with more than 250 employees.

\subsection{Italy}

Companies in Italy were recommended to use the GRI guidelines when compiling sustainability reports (Fogelberg et al., 2013). Mandatory requirements include the Ministerial Decree of 24 January 2008 and the Legislative Decree no. 150/2009. Voluntary disclosure in Italy includes the social reporting standards and social reporting in the public sector as issued by the study group for social reporting (Gruppo Bilancio Sociale - GBS).

\subsection{United Kingdom (UK)}

An array of guidelines can be used by UK companies to report CSR activities. Companies listed on the London Stock Exchange are required to report on GHG emissions. Other mandatory reports include the Quoted Companies GHG Reporting, British Companies Act, UK Corporate Governance Code, Climate Change Act and the Carbon Reduction Commitment (CRC) (Fogelberg et al., 2013:77). Voluntary reports required in the UK include the Environmental Reporting Guidelines based on key performance indicators (KPIs).

\subsection{United States of America (USA)}

The USA is in the process of adapting sustainability reporting and there has been a significant increase over the period 2012 to 2013 (Fogelberg et al., 2013:35). Frameworks used in the USA include the GHG, CDP, GRI, principles of the UN Global Compact and new SASB. Other mandatory requirements include the Dodd-Frank Act, Presidential Executive Order 13514, Sarbanes-Oxley Act (SOX), Clean Air Act (CAA), Clean Water Act (CWA), Toxic Release Inventory (TRI), California Transparency in Supply Chains Act, and the US Environmental Protection Agency Proposed Mandatory Greenhouse Gas Reporting Rule. Other initiatives include the Commission Guidance regarding disclosure related to Climate Change and the Sustainability Accounting Standards Board.

\subsection{India}

Companies in India use the GRI guidelines to prepare reports on sustainability although the interpretation of the parameters of guidelines may vary (Fogelberg et al., 2013). Other reporting guidelines include the Companies Bill, Business Responsibility Reports, DPE Guidelines on CSR, Annual Environmental Audit, Indian Factory's Act, Corporate Responsibility for Environmental Protection (CREP), and the Quarterly Compliance Report. Voluntary requirements include the National Voluntary Guidelines on Social, Environmental and Economic Responsibilities of Business, Guidance Note on Non- 
Financial Disclosure and the Consultative Paper on Corporate Governance Norms (Fogelberg et al., 2013).

\subsection{Japan}

Japan has placed emphasis on energy usage and GHG emissions. Reporting guidelines taken into consideration include CDP, GRI, and ISO 26000. Mandatory requirements include the Law Concerning the Promotion of Business Activities with Environmental Consideration, Pollutant Release and Transfer Register Law (PRTR), Law Concerning the Rational Use of Energy, Act on Promotion of Global Warming Countermeasures, Railway Enterprise Act and the End-of-Life Vehicles (ELV) Recycling Law. Voluntary guidelines include the Environmental Reporting Guidelines (Fogelberg et al., 2013).

\subsection{South Korea}

South Korea has also placed emphasis on GHG emissions and more than 500 firms were required to report on the emissions (Fogelberg et al., 2013). The GRI reporting guidelines were suggested by the Minister. Mandatory reporting in South Korea includes the Green Posting System, and the Social Contribution Performance Posting System. Voluntary requirements include the Environmental Reporting Guidelines and Best Management Sustainable Guidelines, all based on the GRI guidelines.

\subsection{Sweden}

CSR reporting is mandatory for state-owned companies in Sweden and it is recommended that the GRI guidelines be used. Mandatory standards in Sweden include the Annual Accounts Act, Guidelines for External Reporting by State-owned Companies, and Sustainability Goals for State Owned Companies. Voluntary guidelines include the Guidelines on Environmental Information in the Director's Report Section of the Annual Report (Fogelberg et al., 2013).

\section{Reporting according to GRI G4 guidelines on ethics and integrity}

In this study, the focus was on specific areas of reporting, such as ethics and integrity. Companies were reviewed to identify reporting on the core or comprehensive options. The guidelines are set out in Table 1.

Table 1: GRI G4 selected general standard disclosure items

\begin{tabular}{c|l|c|c}
\hline \multicolumn{1}{c|}{ Part } & \multicolumn{1}{|c|}{ Purpose } & Core & Comprehensive \\
\hline & A broad overview of values, standards and & (1) & (3) \\
& norms. Also mechanisms available to seek & G4-G56 & G4-G56 \\
Ethics and Integrity & for advice on ethical behaviour as well as & & G4-G57 \\
& for reporting concerns about unethical & & G4-G58 \\
& behaviour. & & \\
\hline
\end{tabular}

Source: English \& Schooley (2014) 
The G3 and G3.1 guidelines do not require that companies report on ethics and integrity. This became mandatory with the launch of the fourth generation (G4) guidelines. The GRI will allow for a company to transfer to the new guidelines, and in fact required all companies to report on the G4 guidelines from 1 January 2016. The G4 guidelines offer two options to report in accordance with the guidelines. The core option contains the essential elements of sustainability reporting and the comprehensive option supports the core option by requiring disclosure of the company's strategy, analysis, governance, ethics and integrity (GRI, 2015b). The G4 guidelines contain two different types of standard disclosure, namely general standard disclosure and specific standard disclosure. General standard disclosures are applicable to all companies producing sustainability reports. There are seven sub-sections under general standard disclosure, of which governance, ethics and integrity are three. In this study, the focus was specifically on reporting ethics and integrity. Reporting ethics under the core option requires companies to report on guideline G4-56. Companies reporting under the comprehensive option are required to report on G4-56 as well as G4-57 and G4-58. In order to comply with the G4-56 guidelines of the core option, the company needs to indicate the following: how the company's values, principles, standards and norms of behaviour developed over time; how it was approved and how it was implemented; how training was done or is being done with all stakeholders; whether it is required that training be read and signed off; whether an executive-level position was made available for someone to take the responsibility for the code; and whether the codes are available in different languages.

In order to comply with the G4-57 guidelines in accordance with the comprehensive option, the company needs to indicate the following: whether internal or external mechanisms for seeking advice on ethical and lawful behaviour is available to stakeholders; whether an executive-level position was made available for someone to take responsibility for advice-seeking mechanisms; whether all stakeholders were informed about the adviceseeking mechanisms; whether the mechanisms are available in different languages; whether requests for information are treated confidentially; whether the mechanisms allow for anonymous requests for information; the number of requests received; the number or percentage of successfully resolved requests; and the level of satisfaction of stakeholders that used the mechanisms.

In order to comply with the G4-58 guidelines in accordance with the comprehensive option, the company needs to indicate the following: whether internal or external mechanisms exist to report unethical behaviour and other matters that relate to the integrity of the organisation; whether an executive-level position was made available for someone to take responsibility for the mechanisms for reporting concerns; whether the mechanisms are independent of the company or not; whether the mechanisms are available in different languages; whether training was provided to stakeholders; whether reporting concerns are treated confidentially and can be done anonymously; whether the organisation has a non-retaliation policy; the process that is used when investigating concerns; the number of reports received; the number or percentage of successfully resolved reports; and the level of satisfaction of stakeholders that used the mechanisms. 


\section{Reporting according to GRI G4 guidelines on anti-corruption}

Not all companies are required to report on aspects of the specific standard disclosure, only companies that have assessed their business practices and found these items material to the operation thereof. In this study, it was also investigated whether the companies identified during the study found corruption to be a material aspect and whether reporting on corruption was included in the CSR reports. Guidelines are set out in Table 2.

Table 2: GRI G4 specific standard disclosure items

\begin{tabular}{c|c|c|l}
\hline Category & Sub-category & Aspect & \multicolumn{1}{c}{ Indicator } \\
\hline Social & Society & Anti-corruption & Assessment of operations for \\
& & G4-SO3 & risk of corruption \\
& & G4-SO4 & \\
& & G4-SO5 & \\
\hline
\end{tabular}

Source: English \& Schooley (2014:30)

The reporting guidelines on anti-corruption are found under the heading of specific standard disclosures regarding social aspects, under the sub-category society guidelines, in G4-SO3, G4-SO4 and G4-SO5. Only material aspects are reported in the Disclosure on Management Approach (DMA) (GRI, 2015b). The DMA provides the opportunity to the company to explain how economic, environmental and social impacts related to material aspects are managed.

In order to comply with the G4-SO3 guideline under specific standard disclosure, the company needs to provide information regarding the total number or percentage of operational areas assessed for corruption-related risks; and any significant risks identified. In order to manage risks on incidents of corruption, the company needs to implement a system with supporting procedures. This indicator measures the implementation across the company. Risk assessments also aim to detect the potential for incidents of corruption and help the organisation to implement policies and procedures to fight against corruption. When compiling the report the company needs to identify all the areas that were assessed for risk of corruption. The assessment can be a formally focused on corruption or it can include corruption as a risk factor in the overall assessment. Information required for the compilation of the report includes monitoring reports, risk registers and risk management systems (GRI, 2015a).

In order to comply with the G4-SO4 guideline under specific standard disclosure, the company needs to provide the following: information with regard to the communication on anti-corruption policies and procedures to stakeholders; and information with regard to the training of anti-corruption policies and procedures with stakeholders.

Through communication and training, the company can raise internal and external awareness on corruption, which creates the capacity to actively combat corruption. This indicator reveals the proportion of governance body members, employees and other 
stakeholders that are aware of the anti-corruption policies and procedures. Training records can be accessed during compilation of the report (GRI, 2015a).

In order to comply with the G4-SO5 guideline under specific standard disclosure, the company needs to provide the following: information on the number of confirmed incidents of corruption; a report on action taken against guilty individuals or parties; and a report on any legal cases brought against the organisation. When compiling the report, the company should identify the total number of confirmed incidents individually, as well as the nature of these incidents. Information required includes legal department records of cases brought against the organisation or employees or business partners, the minutes of any disciplinary actions taken, and contracts with business partners (GRI, 2015a).

\section{Research objective and research design}

The main objective of this research was to evaluate the level of reporting on aspects such as ethics, integrity and anti-corruption of companies in the motor vehicle manufacturing sector. Content analysis was used as a research method, the analysis focused on documents and records of the selected companies, and boundaries were clearly demarcated. A cross-sectional research approach was followed, where the cohorts were examined at a specific time. Twenty motor vehicle manufacturers that are listed companies and produce integrated reports or financial and corporate social reports were identified through random selection and represent nine different countries.

A checklist of pre-determined criteria based on the literature study and the GRI G4 guidelines was drawn up. The checklist consisted of different sections. Biographical information focused on company-specific information such as where the parent company was based, type of reporting, reporting guidelines used and whether the company information was externally validated. After the biographical information, the rest of the checklist was divided into five sections. The checklist presented questions to which a "present" or "not present" answer was required. This was indicated by a 1 when an item was present in the report, while a 0 indicated that the information was not present in the information obtained.

\section{Results}

\subsection{Biographical information}

Biographical information obtained from the sample indicates that the 20 companies are based in different countries. The data in Figure 1 provides a visual indication of the locality of the parent or holding company. Of the 20 companies, six motor vehicle manufacturing companies are based in Japan, four in Germany, and two companies in Sweden, USA and South Korea respectively. The UK, France, India and Italy all have one motor vehicle manufacturing company represented in the sample. 


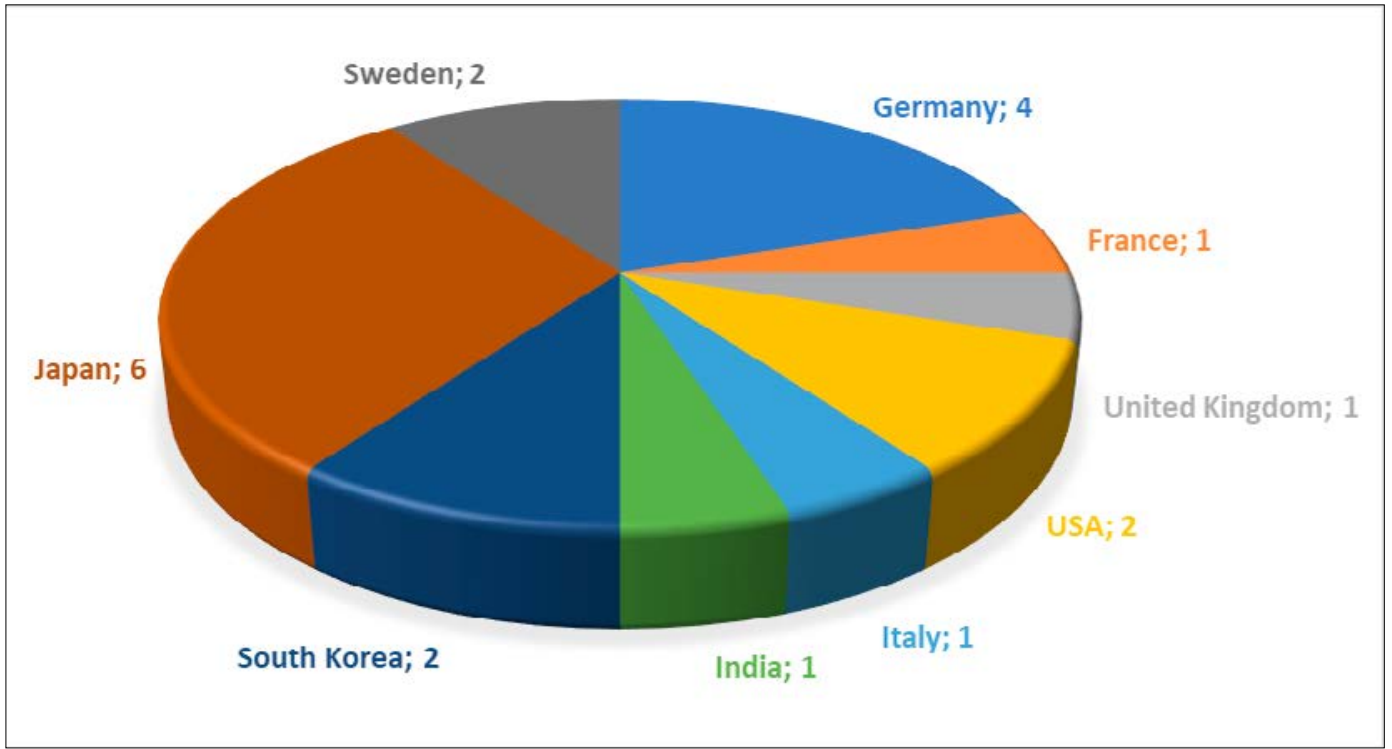

Figure 1: Locality of companies

In some of the companies, such as Volkswagen, different brands belong to the parent company, such as Audi, Porsche and Bentley. Due to the parent/holding company being evaluated in this study, brands with exactly the same CSR report were excluded. Jaguar Land Rover is a UK-based company but was bought over by the Indian company, Tata. The CSR report published for Jaguar Land Rover was exactly the same as for Tata, and therefore Tata was eliminated from the initial sample. Of the 20 companies represented in the sample, 10 companies have more than one brand, namely: Audi, BMW, Daimler, Fiat, GM, Jaguar, Nissan, PSA, Toyota and VW.

The reports published by the companies were reviewed, and 19 of the 20 companies are still issuing separate annual and CSR reports. Only one company, Mitsubishi, has published an integrated report. Information was obtained from CSR reports, with Audi and Daimler also referring to their annual report, and BMW and Ford referring to their annual report as well as their website for governance information.

\subsection{Reporting guidelines}

The reports were evaluated, based on the developed checklist. The data in Figure 2 indicates the reporting guidelines used by the different companies. Fifteen of the 20 companies utilise the GRI guidelines. Seven companies used the GRI G4 as well as the UN Global Compact principles when producing their CSR reports. The companies that used the combination include BMW, Daimler, Ford, GM, Hyundai, SAAB and Volvo. Six companies only used the GRI G4 guidelines, namely: Audi, Fiat, Honda, Jaguar Land Rover, Nissan and Volkswagen. Two companies used only the GRI G3 guidelines, and one company only used the ISO 26000 guidelines. The other companies used combinations of the available guidelines. 


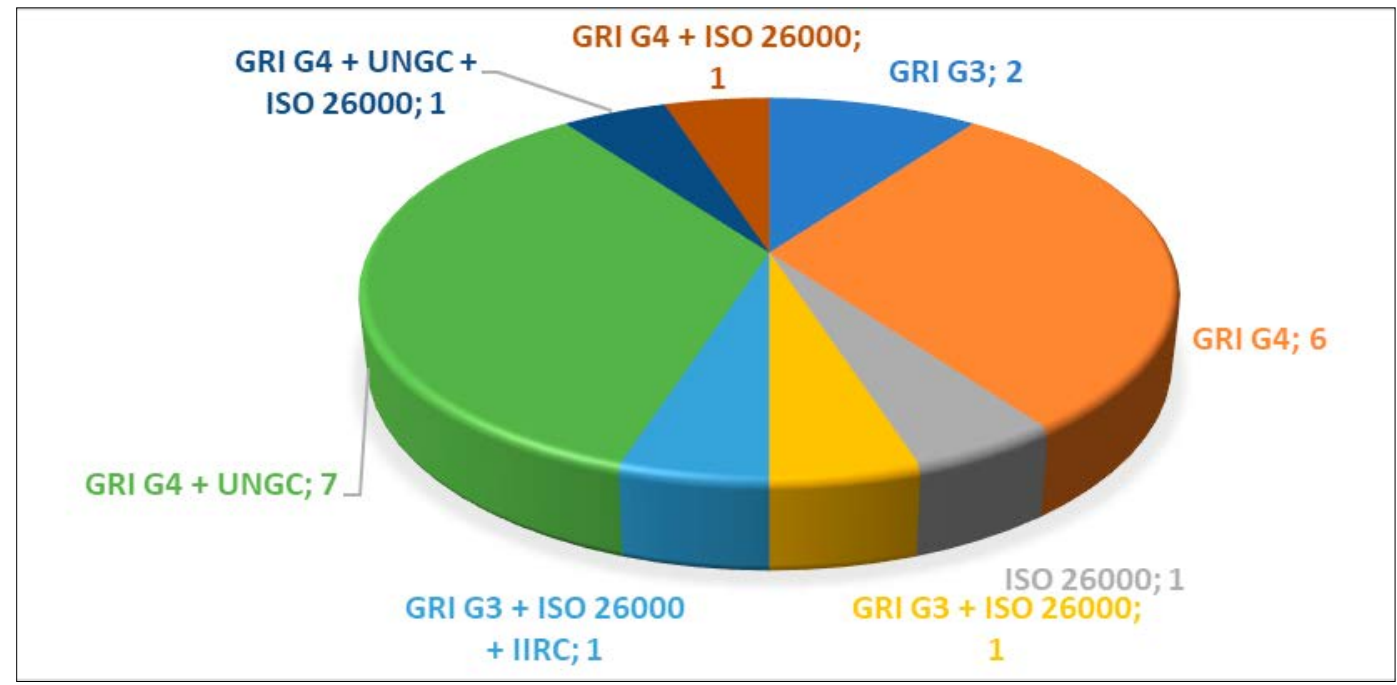

Figure 2: Reporting guidelines use by company

In view of the 18 September $2015 \mathrm{VW}$ emission scandal, it was fascinating to note that Audi withdrew from the UN Global Compact. VW also did not publish a CSR report for 2015. The latest report available for VW was the 2014 report. Sixteen companies submitted reports for 2015, and three companies have already released reports for 2016, being Honda, Kia and Nissan, by the time of this study.

\subsection{Validation}

External validation adds to the credibility of the information disclosed in the CSR reports. From the sample of 20 companies, only 14 had their CSR reports externally validated. The data in Figure 3 indicates which companies obtain external assurance of information represented in the CSR reports.

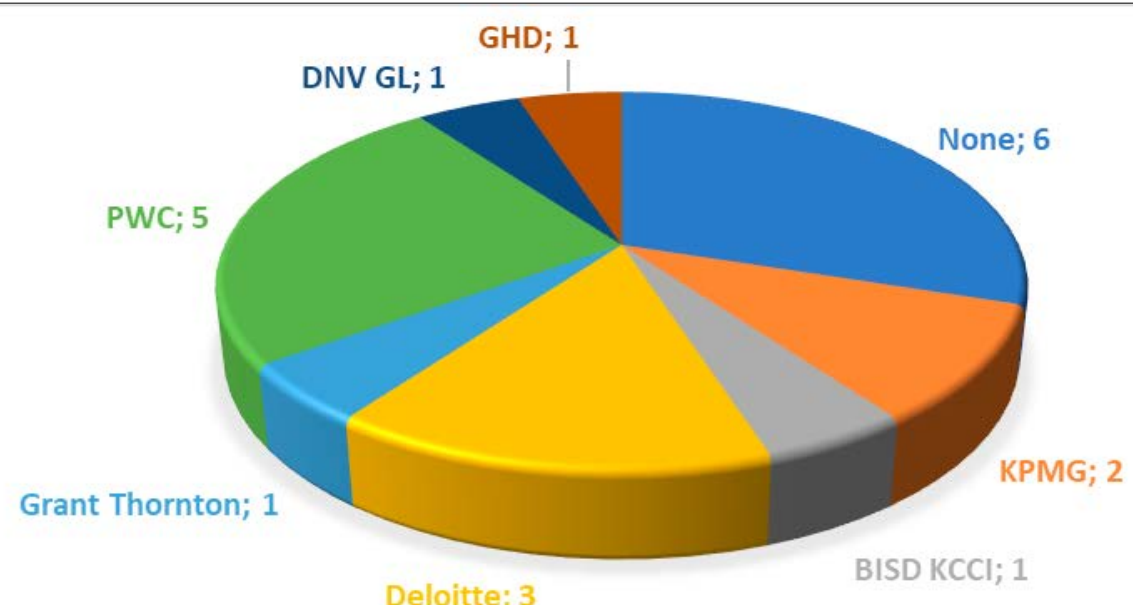

Figure 3: External assurance companies 
The external validation was done by PricewaterhouseCoopers (5 companies), KPMG (2 companies), Deloitte (3), Grant Thornton (1), DNV GL Business Assurance Korea Ltd (1), The Business Institute for Sustainable Development (BISD) managed by the Korea Chamber of Commerce \& Industry (KCCI), and GHD Service Inc. (one company). The six companies that published reports that were not validated from an external source are Ford, Isuzu, Jaguar Land Rover, Mitsubishi, SAAB and Volvo.

\subsection{Organisational values, principles, standards and norms}

This section of the checklist aimed at evaluating the disclosure of information on codes of conduct or codes of ethics as well as to which extent employees, governance board members and business partners were informed about the code and trained in using the code. The section consisted of six questions.

All 20 companies indicated that there was a code of conduct or code of ethics at the company, of which only nine (45\%) had made the code available in different languages. Eighty percent of the companies indicated that training was provided regularly, whereas only $40 \%$ required employees to read the document and sign that they had read and understood the content. It was noted that there was a trend among these companies that training was done electronically, either via e-learning, video clips or e-mail. The companies utilising technology to do training did not indicate whether records were kept of successful completion of the training.

Only $60 \%$ of the companies indicated that a top executive-level position had been created and an employee had been appointed to take full responsibility of the code and the required training. The other companies indicated that there were compliance offices or governance boards, but did not indicate a designated employee.

\subsection{Mechanisms for seeking advice on ethical and lawful behaviour}

This section of the checklist was designed to measure whether the company report, included mechanisms available to employees, governance board members and business partners, to seek advice on ethical and lawful behaviour, as well as all aspects related to company integrity. It also reviewed whether companies made use of mechanisms independent of the company, or whether they only used in-house systems. This section consisted of nine questions aimed at evaluating whether information on these types of mechanisms for seeking advice was disclosed in the annual or CSR report. The first question identified the companies that did a report on the mechanism. The questions that followed indicated percentages of the companies that complied and excluded companies that did not indicate that the mechanisms were present.

Nineteen of the twenty companies indicated that such a mechanism was indeed made available to the stakeholders, and only $37 \%$ had the mechanisms available in different languages. These mechanisms encouraged the use of the facility and included phone lines, e-mail or fax facilities, direct contact with management as well as manuals on ethical and lawful behaviour. 
Fifty-three percent of the companies that had made an advice-seeking mechanism available to the stakeholders had it located at an external source or organisation independent of the company. In the majority of cases, the external companies were law firms who administered and managed the requests submitted via the device.

The sensitivity related to the mechanism indicated that although all companies preferred that individuals disclosed information in person, only $47 \%$ indicated that it allowed anonymous requests for information. Fifty-three percent of the companies indicated that the seeking of advice was treated confidentially.

Fifty-three percent of companies indicated that an executive-level position had been created and that the appointed incumbent was responsible for the advice-seeking mechanism. Where a designated employee had not been assigned, the companies referred to compliance groups or governance board members.

Companies were also required to provide feedback on the usage of the mechanisms, and $37 \%$ of companies indicated figures on the number of stakeholders who had used the mechanism during the year. Only $16 \%$ of companies indicated the number of requests that had been responded to successfully. None of the companies disclosed information on the level of satisfaction of the employees who had used the mechanism to seek advice.

\subsection{Mechanisms to report concerns about unethical or unlawful behaviour}

This section of the checklist reviewed whether companies disclosed information on mechanisms available to employees, governance board members and business partners to report concerns on unethical or unlawful behaviour related to company integrity. This section also evaluated whether the mechanisms were in-house or external and independent of the company. The first question identified companies that had made mechanisms available, while the remainder of the questions were aimed at companies with mechanisms and excluded companies that did not indicate the mechanism in the annual or CSR report. This section consisted of 12 questions.

Nineteen of the twenty companies indicated that there were mechanisms available to stakeholders to report any concerns related to company integrity. Only $32 \%$ indicated that the mechanism was available in different languages. Fifty-eight percent of the companies indicated that the mechanism was independent of the company. As with the mechanism for seeking advice, the majority of the companies indicated that the external body administering and handling the mechanism was a law firm. The majority of the companies referred to hot lines for whistleblowers or just hot lines, but an e-mail and phone call option were also indicated. Some of the companies also expressed their wish that employees would discuss the concern with their immediate management.

Fifty-three percent of the companies indicated that a designated employee was assigned the responsibility of the mechanism, and $74 \%$ indicated that all stakeholders had received training on how and when to use the mechanism. 
The sensitivity with regard to reporting concerns was handled in the same manner as with advice-seeking mechanisms; although companies preferred stakeholders reporting in person, with $58 \%$ indicating that they allowed anonymous reporting of concerns. Fifty-three percent of companies indicated that the reporting of concerns was handled confidentially. Employees who were not allowed to report concerns about ethical or lawful behaviour anonymously might be frightened by the treatment they could receive from the company when reporting incidents or concerns. Companies had to protect such employees and ensure that there would be no punishment or retaliation when stakeholders reported concerns. The company could implement non-retaliation policies to solve the problem. Only $47 \%$ of the companies with mechanisms indicated that they had a non-retaliation policy. Fifty-eight percent of the companies indicated the process that should be followed when a concern or unethical behaviour was reported.

When reviewing the reports for information on the usage of the mechanism, $37 \%$ of companies indicated the number of concerns or reports received via the reporting mechanism. Thirty-two percent indicated the number of reports that were resolved successfully, while none of the companies indicated the level of satisfaction of stakeholders who had made use of the mechanism.

\subsection{Risk assessment related to corruption}

This section focused on the level of disclosure on risk assessments done in the company to determine any significant risks related to corruption. It contained two questions. Only five of the 20 companies (25\%) indicated the number or percentage of units assessed for possible areas where corruption could take place. Of these five companies, only three revealed the risks that were identified. These risks included the $\mathrm{VW}$ emission connection with Audi. Ford identified a contact with government officials as one of the highest risks due to bribery. The PSA Group identified fraud as one of the biggest risks.

\subsection{Anti-corruption policies and procedures}

This section focused on whether companies created awareness among all stakeholders on policies and procedures related to anti-corruption. It consisted of two questions. When reviewing the reports it was found that all the companies had indicated that they communicated information on anti-corruption policies and procedures to all stakeholders. Eighteen of the twenty companies also actively trained stakeholders in the policies and procedures of anti-corruption.

\subsection{Confirmed incidents of corruption}

This section evaluated whether companies reported on confirmed cases of corruption, what action was taken against guilty employees or business partners, as well as what legal action was taken against the company. The section consisted of three questions. Only seven or $35 \%$ of all companies indicated that confirmed incidents of corruption had 
occurred during the period of the report. Only seven or $35 \%$ of all companies indicated what actions were taken against the guilty parties, and only $35 \%$ of all companies indicated pending legal actions against them.

\section{Conclusions}

Insight was gained into the growing need for information about integrity, ethics and anti-corruption within companies, as well as to communicate this to the greater society. Not only will more transparent communication be required by investors looking at investment opportunities, but also by society which has shifted its focus from shortterm profits to long-term sustainability, thereby ensuring that resources are used in such a way that future generations can also benefit. Motor vehicle manufacturing companies feel the pressure, especially with increasing gas emissions and particularly after the VW scandal.

Although sustainability and CSR reporting is still in its infancy, prompt adoption of the notion has been evident, and companies are actively participating in providing the required information. As evident from the results of this study, the majority of companies are aware of the need for more transparent information. Although there are clear guidelines on what to include in their reports, some companies are still not providing the information as recommended by the guidelines and required by greater society.

Company values, principles, standards and norms are of utmost importance. Although this is often only viewed as a code of conduct or a code of ethics, literature defines it as a tool that can assist companies in setting goals, measuring performance and managing the process towards sustainability. All companies indicated that they do have a code of conduct or code of ethics and that the majority trained their stakeholders on a regular basis. The training could be conducted via different mediums, including e-training, video clips, classroom training sessions, and e-mails and training manuals. One of the companies also indicated that current training was done in the form of a game, in order to make it more interesting for the stakeholders. A below-average number of companies indicated that it was required that training guidelines for company values, principles, standards and norms should be read and signed. It was interesting to note the shift from traditional training in classroom style to training done via technology. Online training may be a way of covering larger numbers of employees in order to satisfy compliance requirements. It could also indicate that companies take the information transfer of values seriously and that they are adapting to different formats of transferring such information. However, some areas were not covered by the training and companies should, therefore, ensure that resources are available for employees to seek advice, specifically about ethical and lawful behaviour.

The majority of companies had made mechanisms available to stakeholders to seek advice on such behaviour. Only seven companies indicated that the mechanisms had been made available in different languages. This could imply that the requirement of making the mechanisms available to all stakeholders would not be met. Only half of the sample 
indicated that the mechanisms were independent of the company and were often referred to a law firm.

Sensitivity remained an important aspect, as, without protection, employees would feel uncomfortable about stepping forward and enquiring from or informing authorities of any actions that could jeopardise the reputation of the company. Of the companies that had made mechanisms available to employees, just above average allowed anonymous advice seeking and indicated that reports were treated confidentially. Half of the companies indicated that a designated employee was assigned the responsibility of the advice-seeking mechanism. The importance of this mechanism should not be underestimated as well as whether the employee assigned the duty of overseeing the mechanism could provide valuable management information on risk or concern areas, as indicated in the enquiries. Companies have to provide feedback on the usage of this advice-seeking mechanism, and only $37 \%$ of companies indicated figures on the number of people who had used the mechanism during the year. Of these only, $16 \%$ indicated the number of requests that had been responded to successfully. None of the companies disclosed information on the level of satisfaction of the employees who had used the mechanism to seek advice.

The majority of companies, 19 out of the 20, indicated that mechanisms were available to report on concerns and unethical or unlawful behaviour. However, only a few companies indicated that such mechanisms were available in different languages. More than half of the companies indicated that the reporting mechanisms were independent of the company, and in most cases, these were administered by law firms. Some of the companies indicated that the same mechanisms were used for both seeking advice and reporting concerns. The conclusion is that the advice-seeking mechanism as well as how to close the loop on feedback systems in the companies need more attention in order to be effective.

Having an in-house system could create a perception that reports on unethical behaviour or concerns about company integrity would not be addressed in a proper manner due to companies being sensitive to reputational risk. It can be viewed as a step towards transparency when companies involve independent organisations to manage and administer mechanisms for seeking advice and reporting concerns.

Employees fear retaliation when reporting unlawful actions, hence it will be important that a company protects an employee who draws attention to misconduct. Less than half of the companies indicated that they had a non-retaliation policy in place. Investors might view this as a disadvantage, as there is no protection for employees. This could result in employees not actively assisting in the fight against corruption.

As highlighted in the literature, businesses are guided by law, but society expects more than just legal compliance. Regular and continued risk assessments in the company are of utmost importance if the company aims to meet society's requirements. When reviewing the results from the checklist, very few companies $(25 \%)$ indicated what areas were assessed for risks, and only $15 \%$ indicated significant risks identified. Omitting this type of information can indicate that the assessments were not done. The incidents that were reported included the connection of other brands with Volkswagen due to the emission 
scandal. Government officials' bribery and fraud cases were also identified as important indicators of corruption. These incidents were only mentioned and no in-depth detail was provided.

When reviewing the reports, all the companies indicated that they had policies and procedure on anti-corruption in place. The companies reported that their policies and procedures were communicated to all stakeholders, with $90 \%$ of the companies indicating that training was provided in both policies and procedures. It can be expected that companies will fight against all forms of corruption collectively - an important aspect that investors and greater society would like to be reflected in reports.

When evaluating the company reports according to the checklist, companies disclosed very little information on confirmed incidents of corruption. On average, only $35 \%$ indicated the number or nature of confirmed incidents of corruption, actions taken against the guilty parties, as well as legal action taken against the company. Corruption undermines trust, breaks up relationships and often results in detrimental actions. This is exactly what happened with the VW scandal, where there was an abuse of power for monetary gain. The incident created antagonism among various countries, with some countries only initiating legal action after a year. This deceit from a reputable company would not have been as risky if it were only for monetary gain, but in actual fact, it was impacting on the environment and its sustainability. The cost of this action is still to be determined, but VW has agreed to pay 15.3 billion dollars to settle US federal lawsuits.

The checklist was not designed to evaluate information per country. It was however noticed that Germany and the USA received higher scores than the other countries. It was also observed that none of the companies in Japan, South Korea or Sweden indicated that they did any risk assessments related to corruption. All the countries indicated that there are policies and procedures on anti-corruption and that training was actively done. Companies in Germany disclosed more information on corruption incidents than any of the other countries.

\section{Recommendations}

In some countries, sustainability reporting is not compulsory as yet. However, there is a global movement towards such reporting and a definite increase in support for the Global Reporting Initiative reporting guidelines. Not only is non-financial information important to greater society, but the reviewing of internal processes can also guide companies in many aspects, such as highlighting possible risk areas. There is a growing need from society for more transparent and accurate sustainability reporting. Society is also expecting companies to show commitment and intent to build long-term sustainability by being more accountable, taking responsibility for their actions, and communicating their commitment. Companies should accept responsibility for misconduct that has occurred, disclose such information and respond with appropriate action. Greater society will accept acknowledgement of misconduct more easily when disclosed by the company itself rather than hearing about it in the media. It is recommended that companies 
disclose information on all aspects, as proposed by the reporting guidelines. Although businesses are guided by law, companies should emphasise awareness programmes and training in good business practices. Re-enforcing rules and regulations on a regular basis will lead to such rules becoming a culture. Companies should also assist employees in their fight against corruption by making mechanisms available for information seeking or reporting of distrustful activities. Sharing this information in annual reports will confirm the strong stance of the company on governance aspects. Ultimately, companies should aim to create business integrity, where employees, managers and business partners will do the right thing without anyone looking over their shoulder. The development of a Code of Ethics and reporting about ethics and integrity are recognised ways that companies use to illustrate to their stakeholders their commitment to ethical behaviour, but themselves do not provide any guarantees for ethical behaviour.

\section{References}

Anderson, G.E. \& Varney, R.M. 2015. Sustainability Reporting: Demonstrating commitment and adding value. NACD Directorship, 41(1):58.

Appel, J. \& Plant, K. 2015. A framework for internal auditors to assess ethics in a national public sector department. Southern African Journal of Accountability and Auditing Research, 17(2):57-69.

Bartels, W., Fogelberg, T., Hoballah, A. \& Van der Lugt, C. 2016. Carrots \& Sticks. Global trends in sustainability reporting regulation and policy. https:/home.kpmg.com/xx/en/home/insights/2016/05/carrots-andsticks-global-trends-in-sustainability-reporting-regulation-and-policy.html [Accessed 2 August 2016].

Bouten, L. \& Hoozée, S. 2015. Challenges in Sustainability and Integrated Reporting. Issues in Accounting Education Teaching Notes, 30(4):83-93. https://doi.org/10.2308/iace-51093

Czimbal, B. \& Brooks, M. 2006. Ethics \& Integrity. http://www.abundancecompany.com/ethics_integrity.htm [Accessed 24 July 2016].

English, D.M. \& Schooley, D.K. 2014. The Evolution of Sustainablty Reporting. The CPA Journal, 84(3):26-35.

Eyewitness News. 2016. 'VW crisis won't cause lasting damage to German economy'. http://ewn.co.za/2015/ 10/13/Volkswagen-crisis-wont-cause-lasting-damage-to-German-economy [Accessed 24 August 2016].

Fogelberg, T., Bartels, W., Lemmet, S., Malan, D. \& Van der Lugt, C. 2013. Carrots \& Sticks. Sustainability reporting policies worldwide - today's best practice, tomorrow's trends. http://www.usb.ac.za/governance/ Pages/carrots-and-sticks-sustainability-reporting-policies-worldwide.aspx [Accessed 2 August 2016].

Godha, A. \& Jain, P. 2015. Sustainability Reporting Trend in Indian Companies as per GRI Framework: A Comparative Study. South Asian Journal of Business and Management Cases, 4(1):62-73. https://doi. org/10.1177/2277977915574040

Greenhouse Gas Protocol. 2016. About the GHG Protocol. http://www.ghgprotocol.org/about-ghgp [Accessed 16 August 2016].

GRI (Global Reporting Initiative). 2015a. G4 Sustainability reporting guidelines. Implementation manual. https://www.globalreporting.org/standards/g4/Pages/default.aspx [Accessed 5 February 2016].

GRI (Global Reporting Initiative). 2015b. G4 Sustainability reporting guidelines. Reporting principles and standard disclosures. https://www.globalreporting.org/standards/g4/Pages/default.aspx [Accessed 3 February 2016].

GRI and ISO 26000. 2010. How to use the GRI guidelines in conjunction with ISO 26000. https://www. globalreporting.org/Pages/resource-library.aspx?resSearchMode=resSearchModeText\&resSearchText=G $\mathrm{RI}+\mathrm{and}+\mathrm{ISO}+26000 \% 3 \mathrm{a}+\mathrm{How}+\mathrm{to}+$ use +the+GRI [Accessed 29 August 2016].

His Royal Highness the Prince of Wales. 2015. Accounting for sustainability. http://www.accountingfor sustainability.org/about-us [Accessed 26 October 2015]. 
Hughen, L., Lulseged, A. \& Upton, D.R. 2014. Improving stakeholder value through sustainability and integrated reporting. The CPA Journal, 84(3):57-81.

Integrated reporting. 2013. The international IR framework. www.theiirc.org [Accessed 2 August 2016].

Institute of Directors. 2016. King IV Report on Corporate Governance for South Africa. http://www.iodsaco.za/ page/kingIVReport [Accessed 4 October 2017]

ISO 26000 Social Responsibility. 2010. ISO 26000 project overview. www.iso.org/iso/en/iso_26000_project_ overview.pdf [Accessed 29 August 2016].

Jondle, D. Ardichvili, A. \& Mitchell, J. 2014. Modelling Ethical Business Culture: Development of the Ethical Business Culture Survey and its use to validate the CEBC Model of Ethical Business Culture. Journal of Business Ethics, 119(1):29-37.

Junior, R.M., Best, P.J. \& Cotter, J. 2014. Sustainability reporting and assurance: a historical analysis on a world-wide phenomenon. Journal of Business Ethics, 120(1):1-11. https://doi.org/10.1007/s10551-013-1637-y

Kehbila, A.G., Ertel, J. \& Brent, A.C. 2010. Corporate sustainability, ecological modernization and the policy process in the South African automotive industry. Business Strategy and the Environment, 19(7):453-465.

Lynch, M.F., Lynch, N. \& Casten, D. 2014. The expanding use of sustainability reporting. The CPA Journal, 84(3): 19-24.

Mintz, S.M. 2011. Triple bottom line reporting for CPAs. The CPA Journal, 81(12):26-33.

Mironiuc, M., Chersan, I.-C. \& Robu, I.-B. 2013. Ethics in Providing Non-Audit Services to Ensure Transparency in Financial Reporting. Procedia-Social and Behavioral Sciences, 81:474-478. https://doi.org/10.1016/j. sbspro.2013.06.463

Mpinganjira, M., Roberts-Lombard, M., Wood, G. \& Svensson, G. 2015. Embedding the ethos of codes of ethics into corporate South Africa: current status. European Business Review, 28 (3):333-351. https://doi. org/10.1108/EBR-04-2015-0039

Navratil, S. 2007. The difference between ethics and integrity. http://www.zoomstart.com/ethics-and-integrity/ [Accessed 24 July 2016].

Owen, G. 2013. Integrated reporting: A review of developments and their implications for the accounting curriculum. Accounting Education, 22(4):340-356. https://doi.org/10.1080/09639284.2013.817801

Pandit, G.M. \& Rubenfield, A.J. 2016. The Current State of Sustainability Reporting by Smaller S\&P 500 Companies: What Do Businesses Choose to Disclose? The CPA Journal, 86(6):52-57.

Romero, S., Jeffers, A.E. \& DeGaetano, L.A. 2014. An overview of sustainability reporting practices. The CPA Journal, 84(3):68-71.

Russo-Spena, T., Tregua, M. \& De Chiara, A. 2016. Trends and Drivers in CSR Disclosure: A Focus on Reporting Practices in the Automotive Industry. Journal of Business Ethics,1-16. https://doi.org/10.1007/s10551-0163235-2

Schooley, D.K. \& English, D.M. 2015. SASB: A pathway to sustainability reporting in the United States. The CPA Journal, 84(4):22-27.

Siew, R.Y. 2015. A review of corporate sustainability reporting tools (SRTs). Journal of Environmental Management, 164:180-195.

Sukitsch, M., Engert, S. \& Baumgartner, R.J. 2015. The Implementation of Corporate Sustainability in the European Automotive Industry: An Analysis of Sustainability Reports. Sustainability, 7(9):11504-11531.

Tinjala, D.-M., Pantea, L.M. \& Alexandru, B. 2015. Business Ethics and Integrity: A Case Study on 300 US Listed Companies. Studia Universitatis “Vasile Goldis" Arad. Economics Series, 25(2):63-80.

Transparency International. 2016. What is corruption? http://www.transparency.org/what-is-corruption/ [Accessed 24 July 2016].

Tschopp, D. \& Huefner, R.J. 2015. Comparing the Evolution of CSR Reporting to that of Financial Reporting. Journal of Business Ethics, 127(3):565-577.

Walcher, A., Stempkowski, R. \& Apfalter, M. 2013. Prevent Corruption - Measures to increase integrity in organizations. Life-cycle and sustainability of civil infrastructure systems, 468. 